\title{
Chlamydial Antibiotic Resistance and Treatment Failure in Veterinary and Human Medicine
}

\author{
Nicole Borel $^{1}$ - Cory Leonard ${ }^{1} \cdot$ Jessica Slade $^{2} \cdot$ Robert V. Schoborg $^{2}$ \\ Published online: 3 February 2016 \\ (C) The Author(s) 2016. This article is published with open access at Springerlink.com
}

\begin{abstract}
The Chlamydiaceae are widespread pathogens of both humans and animals. Chlamydia trachomatis infection causes blinding trachoma and reproductive complications in humans. Chlamydia pneumoniae causes human respiratory tract infections and atypical pneumonia. Chlamydia suis infection is associated with conjunctivitis, diarrhea, and failure to gain weight in domestic swine. Chlamydial infections in humans and domesticated animals are generally controlled by antibiotic treatment - particularly macrolides (usually azithromycin) and tetracyclines (tetracycline and doxycycline). Tetracycline-containing feed has also been used to limit infections and promote growth in livestock populations, although its use has decreased because of growing concerns about antimicrobial resistance development. Because Sandoz and Rockey published an elegant review of chlamydial antimicrobial resistance in 2010, we will review the following: (i)
\end{abstract}

This article is part of the Topical Collection on Bacteriology

Robert V. Schoborg

schoborg@etsu.edu

Nicole Borel

n.borel@access.uzh.ch

Cory Leonard

coryann.leonard@uzh.ch

Jessica Slade

jordanja@goldmail.etsu.edu

1 Institute of Veterinary Pathology, Department of Pathobiology, Vetsuisse Faculty, University of Zurich, Winterthurerstrasse 268, CH-8057 Zurich, Switzerland

2 Department of Biomedical Sciences, Center of Excellence for Inflammation, Infectious Disease and Immunity, Box 70579, Quillen College of Medicine, East Tennessee State University, Box 70579, Johnson City, TN 37614-0579, USA antibiotic resistance in C. suis, (ii) recent evidence for acquired resistance in human chlamydial infections, and (iii) recent non-genetic mechanisms of antibiotic resistance that may contribute to treatment failure.

Keywords Chlamydia trachomatis . Chlamydia muridarum . Chlamydia suis · Treatment failure · Tetracycline resistance · Gastrointestinal infection

\section{Introduction}

The Chlamydiaceae are Gram-negative, obligate intracellular bacteria with a complex developmental cycle. After the infectious elementary body (EB) enters a host cell, EB-containing endosomes fuse to form a membrane-bound, cytoplasmic inclusion. Within the inclusion, EB develop into larger, noninfectious reticulate bodies (RB). RB use host cell metabolites to grow, and divide. After 30-70 h, RB mature into infectious $\mathrm{EB}$, which are released from the infected host cell. Under adverse environmental conditions, developing Chlamydiae may enter a state referred to as persistence or, more recently, as chlamydial stress or the aberrant RB phenotype [1]. Stressed Chlamydiae remain viable, but do not develop into $\mathrm{EB}$ and are non-infectious. They have a characteristic appearance and are termed aberrant RB/aberrant bodies (AB). Antibiotic exposure is one stressor that can induce this response. For example, penicillin $\mathrm{G}$ elicits the $\mathrm{AB}$ phenotype for up to 9 months in culture. When penicillin is removed, the Chlamydiae resume normal development and produce EB (reviewed in $[2,3])$. Exposure to other $\beta$-lactam antibiotics, including amoxicillin, induces the $\mathrm{AB}$ phenotype in culture [4] and in vivo [5].

Chlamydiae cause asymptomatic infection, as well as acute and chronic diseases affecting different tissues, in humans and 
other animal species. Chlamydia trachomatis serovars A-D cause trachoma, the most common infectious form of human blindness. In 2009 , there were $\approx 40$ million cases of active trachoma worldwide [6]. C. trachomatis serovars D-K and L1-L3 primarily cause human genital tract infections, with $\approx 105.7$ million cases worldwide in 2008 [7]. Manifestations of genital C. trachomatis infection range from urethritis and epididymitis in men to cervicitis, infertility, and ectopic pregnancy in women [8]. C. trachomatis may be the most costly non-viral sexually transmitted infection, with cases from 2008 alone resulting in a total lifetime direct medical cost of $\approx \$ 516$ million in the US [9]. Chlamydia pneumoniae causes human respiratory infections and atypical pneumonia. Recent seropositivity studies [10-12] indicate that $>50 \%$ of adults have been $C$. pneumoniae exposed, confirming earlier observations [13]. In the USA, azithromycin (AZM) and doxycycline (DOX) are treatments of choice for $C$. trachomatis infections in adults, though erythromycin, levofloxacin, and ofloxacin are alternatives. AZM is recommended for treatment of pregnant women, with amoxicillin and erythromycin as alternatives [14]. Atypical pneumonia is often treated empirically with AZM because it covers multiple organisms, including C. pneumoniae. DOX is also a first-line antibiotic for $C$. pneumoniae (reviewed in [15••]).

Chlamydial infections occur in a wide range of animal species, including mammals, birds, fish, marsupials, insects, and amoebae. Pigs are of particular economic importance and can become infected with Chlamydia suis, Chlamydia pecorum, Chlamydia psittaci, and Chlamydia abortus. C. suis is the major pig pathogen, often occurring in mixed infections with other chlamydial species. Manifestations of C. suis infection include respiratory disease, diarrhea, conjunctivitis, and reproductive disorders, while sub-clinical intestinal infections may impair health and cause economic loss (reviewed in [16]). C. suis is endemic in pig farms and wild boar populations worldwide. Though zoonotic transmission of $C$. suis from pigs to humans has not yet been demonstrated [16], its DNA has been detected in conjunctival swabs of Nepalese trachoma patients [17] and Belgian slaughterhouse workers [18]. However, the low amount of C. suis DNA detected in slaughterhouse employee eye swabs may result from hand-toeye "contamination" rather than true infection [18, 19]. Though limited information [20-22] is available concerning antibiotic sensitivity/resistance in other veterinary Chlamydiae, we will focus on that in C. suis because of space constraints.

\section{Antibiotic Resistance in $C$. suis}

The C. suis prototype strain S45 was isolated from feces of an asymptomatic pig in Austria in the late 1960s and is tetracycline (TET) sensitive. C. suis strains are generally regarded as genetically diverse with variations in virulence, however, genomic data to support this prediction are unavailable. Only one partial draft $C$. suis genome (strain MD56 isolated from a pig with conjunctivitis) has been published [23]. Other $C$. suis strains isolated in the USA, Austria, Germany, and Italy, (except S45) originated from pigs presenting with conjunctivitis, enteritis, respiratory disease, or reproductive failure [16].

Tetracyclines have been used since the 1950s to treat human and animal chlamydial infections, particularly in livestock. In the past, livestock feed has been TETsupplemented to prevent infections and promote growth. Tetracyclines inhibit bacterial protein synthesis by binding to the small ribosomal subunit, have broad-spectrum anti-microbial activity, are inexpensive, and have low toxicity [24, 25]. However, their wide use in pig production has facilitated selection of resistant bacteria, with significant implications for human health. Increasing concerns about this practice led to a ban of the sub-therapeutic application of tetracyclines in Europe in the 1970s [24]. The mechanisms by which bacteria obtain resistance to tetracyclines include efflux pumps, drugmodifying enzymes, target mutation, and the employment of specialized ribosomal protection proteins [25].

Genetically stable TET resistance $\left(\mathrm{Tet}^{\mathrm{R}}\right)$ was first described in C. suis strains from diseased and apparently healthy pigs in the USA. Eight $\mathrm{Tet}^{\mathrm{R}}$ strains were isolated from pig farms in Nebraska and Iowa and homotypic $\mathrm{Tet}^{\mathrm{R}}$ was retained after ten to 15 passages in TET-free medium. Six of these eight strains were also sulfadiazine resistant [26]. Two of these $\mathrm{Tet}^{\mathrm{R}}$ strains (R19 and R27) grew in culture at up to $4 \mu \mathrm{g} / \mathrm{mL} \mathrm{TET}$, but not at $5 \mu \mathrm{g} / \mathrm{mL}$. In contrast, C. suis $\mathrm{S} 45$ was sensitive to $0.25 \mu \mathrm{g} /$ $\mathrm{mL}$ TET. Chlamydial inclusions exposed to increasing TET concentrations contained larger numbers of $\mathrm{AB}$. Upon TET removal, the $\mathrm{AB}$ reverted to typical $\mathrm{RB}$ and continued normal development. Furthermore, C. suis $\mathrm{R} 19$ and C. trachomatis L2 occupied the same intracellular vacuole when HeLa cells were sequentially infected with both species [27].

The stable C. suis $\mathrm{Tet}^{\mathrm{R}}$ phenotype was later associated with the resistance gene tet $C$ [28]. Seven $\mathrm{Tet}^{\mathrm{R}}$ strains from the USA each contained one of four related, chromosomally-inserted genomic islands. All 7 resistant isolates carried the tet $C$ gene, encoding a TET efflux pump, as well as the TET repressor gene tet $R$. The genomic islands also shared high nucleotide sequence identity with other Gram-negative bacterial resistance plasmids. These integrated C. suis $\mathrm{Tet}^{\mathrm{R}}$ genomic island/plasmid-like elements were the first example of antibiotic resistance acquired in an obligate intracellular bacterium through horizontal gene transfer. Three of the four tet $C$ islands also carried a novel insertion sequence homologous to the IScs 605 family of insertion sequences of Gram-negative bacteria. All of these genomic islands were inserted at the same position within the chromosome of $\mathrm{Tet}^{\mathrm{R}}$ C. suis strains, interrupting a homologue of the invasion gene (inv) from the Yersiniae [28]. 
Given that most $C$. suis strains are TET sensitive, from where $\operatorname{did} \mathrm{Tet}^{\mathrm{R}} C$. suis strains acquire these genomic islands? The chlamydial tet $C$ islands have $>99 \%$ identity with a resistance plasmid (pRAS3.2) from Aeromonas salmonicida [28]. The plasmid is integrated into the genomic island IScs605, which also encodes the transposase responsible for integration of these genomic islands into the chlamydial chromosome [29]. More recently, the Gram-negative bacterium Laribacter hongkongenesis, which is associated with human gastroenteritis and found in freshwater fish, has been viewed as a potential donor for IScs605. The L. hongkongenesis IScs605 shared $100 \%$ nucleotide identity to that from $C$. suis. Pig industry feeding practices that rely upon prophylactic TET delivery and use of fish as a feeding source may have facilitated acquisition of DNA from fish bacteria, like A. salmonicida or L. hongkongenesis, by C. suis infecting the pig gastrointestinal (GI) tract (reviewed in [30]). However, the proposed mechanism of acquisition of the $\mathrm{Tet}^{\mathrm{R}}$ islands by $C$. suis remains speculative.

In vitro experiments have demonstrated horizontal transfer of Tet $^{\mathrm{R}}$ from $C$. suis to human clinical strains of $C$. trachomatis following co-culture. In contrast, $\mathrm{Tet}^{\mathrm{R}}$ transfer from C. suis to Chlamydia caviae, the guinea pig chlamydial pathogen, was not observed [31]. In a more recent study examining horizontal gene transfer of $16 \mathrm{~S}$ rRNA in prokaryotic organisms, four strains of C. trachomatis were found to have 16S rRNA genes from $C$. suis [32]. These data indicate gene transfer between $C$. suis and $C$. trachomatis occurs in nature and increases concern that antibiotic resistance genes will be transferred into C. trachomatis, either from C. suis or from other Chlamydiae.

After $\operatorname{Tet}^{\mathrm{R}}$ C. suis strains were described in the USA, similar strains were reported in Italy [33], Belgium [16], and Switzerland [34]. In Italy, 14 C. suis strains isolated from pigs with conjunctival and/or reproductive disorders reared in four different farms carried a tet $C$ gene identical to tet $C$ from the original US strains [33]. In vitro DOX minimal inhibitory concentration (MIC) and minimal bactericidal concentration (MBC) values ranged from 4-8 $\mu \mathrm{g} / \mathrm{ml}$ for 12 of these isolates. Interestingly, two of the 14 tet $C$-positive $C$. suis strains (MS9 and MS14) showed lower MIC and MBC values (0.5 and $1.0 \mu \mathrm{g} / \mathrm{mL}$, respectively) indicating partial DOX sensitivity [33]. The same 14 C. suis isolates were later tested against levofloxacin, DOX, and rifaximin, an antimicrobial that is non-absorbable after oral administration and locally active inside the intestinal tract [35]. Rifaximin showed good in vitro activity against all $14 \mathrm{Tet}^{\mathrm{R}}$ strains, with MIC and MBC values from $0.25-1 \mu \mathrm{g} / \mathrm{mL}$. Levofloxacin MIC and MBC values ranged from $0.5-1 \mu \mathrm{g} / \mathrm{mL}$, whereas those for DOX ranged from $4-16 \mu \mathrm{g} / \mathrm{mL}$, except for the MS9 and MS14 strains described above [35].

A recent report by Borel et al. was the first description of $\mathrm{Tet}^{\mathrm{R}}$ C. suis isolation from swine with conjunctivitis and diarrhea on a Swiss farm. Ocular and fecal excretion was observed both before and after TET treatment. Though clinical signs disappeared after treatment, $C$. suis was not eliminated and strains harboring the tet $C$ gene were positively selected. This rapid selection for $\mathrm{Tet}^{\mathrm{R}} C$. suis strains was surprising and possibly facilitated by close contact between pigs and TET-mediated selective pressure [34]. More recently, Tet $^{\mathrm{R}}$ C. suis strains were identified in sow vaginal/rectal swabs and boar semen obtained from four pig breeder-fattener farms located in Israel, Cyprus, and Belgium reporting reproductive failures. Notably, the Israeli farm used boar semen imported from a German pig insemination center [36]. In another recent study, $C$. suis was detected via real-time PCR in vaginal swabs from Dutch pigs with reproductive failure and in conjunctival swabs of asymptomatic employees from a Belgian pig slaughterhouse. The tet $C$ gene was present only in Dutch porcine C. suis isolates and not in human isolates from Belgium [19]. In an additional study, three of 15 C. suis strains isolated from rectal swabs of Belgian slaughter pigs (from three of ten farms) were tet $C$ positive. However, none of the employees' eyes harbored resistant strains [18]. Thus, whether Tet ${ }^{\mathrm{R}}$ C. suis strains infect humans, thereby potentially facilitating transfer of TET resistance genes to human Chlamydiae, remains an open question.

\section{Antibiotic Resistance and Treatment Failure in Chlamydial Species that Impact Human Health}

C. trachomatis and C. pneumoniae have in vitro sensitivity to a wide range of antibiotic classes, including macrolides, tetracyclines, rifamycins, and quinolones (reviewed in [15••]). In vitro exposure to several $\beta$-lactam antibiotics causes C. trachomatis RB to convert to the AB phenotype [4]. When cultured in the presence of sub-inhibitory antibiotic concentrations, $C$. trachomatis can become resistant to rifamycins [via mutations in the RNA polymerase $\beta$-subunit gene rpoB], macrolides [via 23S rRNA gene mutations], and quinolones [via mutations in the DNA gyrase gene gyrA]. However, as of 2010, there was no convincing evidence for in vivo development of homotypic resistance in human chlamydial species (reviewed in [30]). More recent studies of chlamydial strains isolated from infected patients after therapy have also failed to identify resistant organisms. Hong et al. compared $C$. trachomatis serovar A/B strains isolated during an Ethopian trachoma control effort. Analysis of seven strains isolated from previously AZM- or TET-treated patients showed no MIC increase for either drug compared to control strains from untreated communities [37]. A larger study confirmed these results, with none of 15 strains isolated posttreatment failure showing DOX or AZM resistance after a Tanzanian mass-treatment program [38•]. Additionally, a study of 24 C. trachomatis genital strains collected in 
Croatia, which has the highest AZM use in Europe, identified no AZM- or DOX-resistant strains [39]. Similar studies conducted from 1994-2000 on C. pneumoniae strains isolated from patients with community-acquired pneumonia also revealed no evidence for homotypic resistance (reviewed in $[15 \bullet \cdot])$. Thus, despite the observation of acquired $\operatorname{Tet}^{\mathrm{R}}$ in C. suis, human chlamydial species have, fortunately, not yet crossed this Rubicon.

Published data suggest that treatment failure is a significant problem during human chlamydial infections. For example, Golden et al. observed an $8 \%$ failure rate using recommended treatment regimens for genital $C$. trachomatis infection in women who had not reported subsequent sexual activity [40]. More recently, $13.7 \%$ of women experienced treatment failure for $C$. trachomatis genital infection, despite reporting no post-treatment sexual contact and full medication compliance [41]. A recent review suggests treatment failure rates from 5-23\%, depending upon the patient population examined [42]. Although it remains difficult to discriminate from post-treatment reinfection or lack of treatment compliance, most retrospective studies suggest true treatment failure occurs in humans [43]. Since homotypic antibiotic resistance has not yet been documented in C. trachomatis or C. pneumoniae, investigators are exploring alternative mechanisms including the following: (i) development of heterotypic antibiotic resistance (perhaps due to slower growth in certain environments or entry into a stress response in which the organisms are refractory to antibiotic treatment) and (ii) infection of anatomic sites where Chlamydiae are protected from antibiotics. Notably, these mechanisms are not mutually exclusive and could occur in vivo, increasing the difficulty of determining which (if any) contribute to treatment failure.

Heterotypic resistance, in which a subset of individual organisms within a population exhibit reduced antibiotic sensitivity, is one proposed mechanism for treatment failure in humans (reviewed in [42, 44]). Such resistance can be conferred by phenotypic changes in a stressed bacterial population. Bhengraj et al. isolated $C$. trachomatis strains from recurrently infected female patients that had in vitro MIC values for AZM and DOX of up to $8 \mu \mathrm{g} / \mathrm{ml}$, compared to $0.12-0.25 \mu \mathrm{g} / \mathrm{ml}$ for a sensitive serovar D control strain. In the absence of genetic data, the authors postulate heterotypic rather than homotypic resistance [45]. O'Neill et al. recently published a sensitivity and genomic analysis of two clinical $C$. trachomatis strains (IU824 and IU888) previously reported to be $\mathrm{Tet}^{\mathrm{R}}$. MIC and titer assays revealed that neither strain exhibited phenotypic $\mathrm{Tet}^{\mathrm{R}}$ in vitro. Whole genome sequencing did not reveal any known $\mathrm{Tet}^{\mathrm{R}}$ element, although single nucleotide polymorphisms were observed in the $23 \mathrm{~S}$ ribosomal RNA (rRNA) gene in both strains. The authors concluded that the observed resistance was heterotypic and unlikely to result from genetic changes [46]. Thus, it seems likely that heterotypic resistance contributes to treatment failures observed in humans.
Several recent cell culture studies have also illuminated mechanisms by which developing Chlamydiae might escape antibiotic action. Törmäkangas et al. infected Calu-3 human lung epithelial cells cultured on either semi-permeable inserts (polarized orientation) or plastic dishes (flat, non-polarized cultures) with $C$. pneumoniae. Polarized Calu-3 cultures produced fewer infectious EB than did "flat" cultures, suggesting that $C$. pneumoniae development differs when host cells are grown in the more biologically relevant polarized condition. Notably, the DOX MBC (minimal antibiotic concentration that eliminated EB production) was $>33$-fold higher in polarized compared to flat Calu-3 cells, indicating that C. pneumoniae is less antibiotic sensitive when growing in polarized cells [47]. Oxygen concentration also alters chlamydial antibiotic sensitivity in culture. Although MICs for DOX, AZM, moxifloxacin, and rifampin for C. trachomatis L2 are essentially identical under normoxic $\left(20 \% \mathrm{O}^{2}\right)$ and hypoxic $\left(2 \% \mathrm{O}^{2}\right)$ conditions; MBC assays reveal that DOX and AZM are significantly less effective at reducing EB titer during hypoxia. In contrast, moxifloxacin and rifampin MBCs are similar under hypoxic and normoxic conditions. Hypoxia upregulates expression of the host cellular ATP-binding cassette $(\mathrm{ABC})$ transporter protein MDR-1, which may reduce the anti-chlamydial effect of DOX [48]. Interestingly, when cultures of non-replicating, interferon- $\gamma$-stressed C. trachomatis are used as drug targets, DOX is more efficient at reducing EB production under hypoxic, compared to normoxic, conditions [49]. Therefore, local differences in $\mathrm{O}^{2}$ concentration or infected host cell developmental state could provide protected "pockets" within infected tissues where Chamydiae can survive antibiotic exposure.

In culture, chlamydial stress response initiation halts the developmental cycle and the Chlamydiae enter a reversible, non-replicating but viable state. Entry into the AB phenotype also increases resistance of (i) C. pneumoniae to AZM and ofloxacin [50], (ii) C. trachomatis serovar E to AZM [51], and (iii) C. trachomatis L2 to DOX [52]. Stressed chlamydiae are more AZM-resistant in vivo as well. Developing Chlamydiae within the genital tract of Chlamydia muridarum-infected, amoxicillin-treated mice enter the stressed state [5]. Furthermore, the AZM therapy failure rate increases from $9 \%$ in productively infected animals to $22 \%$ in mice infected with amoxicillin-stressed Chlamydiae [53•]. Chlamydial forms with morphologic alterations consistent with stress induction have been observed in tissue samples from chlamydia-infected humans [54, 55, 56 $]$, pigs [57] and mice $[5,58]$. Notably, nutrient-starvation, as well as interferon and $\beta$-lactam antibiotic exposure, all induce chlamydial stress in culture (reviewed in [2,3]) and occur in vivo. Thus, variation in local conditions may also increase treatment failure in vivo via chlamydial stress-induced heterotypic resistance [42, 44].

Another intriguing possibility is that chlamydiae infecting specific anatomical sites are protected from antibiotics. These 
tissues then serve as a reservoir from which the genital tract is "reseeded" after treatment cessation. Recent work has provided compelling data indicating the GI tract is one such protected site. Natural GI infection by chlamydial species that infect animals is well documented (reviewed in [59••]). In an extension of previous studies demonstrating long-term chlamydial GI colonization in mice [60, 61], Yeruva et al. demonstrated that oral inoculation with as little as 100 IFU of C. muridarum established GI infection in mice for at least 75 days pi [62]. A single oral $80-\mathrm{mg} / \mathrm{kg}$ AZM dose eliminated vaginal EB shedding from $C$. muridarum vaginally infected mice but failed to eradicate infectious EB from cecal tissue in orally infected animals. HPLC analyses indicated AZM levels in cervical and cecal tissue were similar, suggesting similar drug penetration in both tissues. Conversely, DOX treatment eliminated both genital shedding from vaginally infected mice and cecal EB production in orally infected mice. The authors concluded that: (i) chlamydiae harbored within the GI tract are more AZM resistant than those in the genital tract and (ii) DOX more effectively eradicates GI chlamydial infection. They also hypothesized that infectious Chlamydiae shed from the GI tract after AZM treatment may re-infect the genital tract [63••]. Over $70 \%$ of women with genital chlamydial infection tested positive for rectal infection in the absence of reported anal-receptive intercourse $[64,65]$, which is consistent with prediction that GI/genital auto-inoculation occurs in humans. Importantly, AZM treatment failure in rectal infections may be as high as $22 \%$ [66]. Both a recent meta-analysis [67••] and a mathematical modeling study [68] support use of DOX rather than AZM for $C$. trachomatis rectal infection treatment. Though the need for additional case controlled studies was stressed, this recommendation was also echoed in a recent review by Hocking et al. [44].

In humans, genital to GI chlamydial transmission seems most likely to occur during oral sex, though if pharyngeal colonization occurs [69], such contact could also promote GI to genital transmission. In contrast, post-treatment GI to genital auto-inoculation in women most likely results from genital contact with EB-containing GI secretions (reviewed in [59••]). If so, post-treatment auto-inoculation should be more frequent in women than men - which is supported by data demonstrating lower treatment failure in genitally infected men than women [40]. In female mice, auto-inoculation is likely mediated by contaminated GI secretions (GI to genital) or grooming (genital to GI). Recent in vivo imaging studies, however, suggest an additional route. Luciferase-expressing C. muridarum rapidly colonizes the murine GI tract for up to 100 days after vaginal inoculation. When auto-inoculation is prevented by fitting mice with Elizabethan collars, or Chlamydiae are introduced directly into the upper genital tract, GI infection is still observed. These data suggest that C. muridarum may spread to the GI tract via a systemic route, though the authors point out that $C$. muridarum and
C. trachomatis may differ in this respect [70•]. However, it seems prudent to evaluate whether systemic spread of C. trachomatis from the genital tract to the GI tract occurs in humans.

\section{Conclusions}

The recent emergence of $\mathrm{Tet}^{\mathrm{R}}$ C. suis strains raises concerns that pigs might be a reservoir for chlamydial $\mathrm{Tet}^{\mathrm{R}}$ determi- $^{-}$ nants. However, detailed assessments of (i) the distribution of $\mathrm{Tet}^{\mathrm{R}}$ chlamydial strains in wild and domestic pigs, and (ii) herd-related risk factors associated with $\mathrm{Tet}^{\mathrm{R}}$ acquisition are lacking. The possibility that other animal Chlamydiae, such as C. abortus or C. psittaci, carry TET (or other) resistance determinants is also unexplored. Finally, the largelyenvironmental chlamydia-like organisms (CLOs), are also emerging pathogens [71•]. Those CLOs tested to date appear to have antibiotic resistance patterns similar to those of the traditional Chlamydiaceae, with the exception of Estrella lausannensis, which carries a single mutation in the $23 \mathrm{~S}$ rRNA gene and is AZM-resistant [72]. Unlike C. trachomatis, CLOs are also generally fluoroquinolone resistant $[73,74]$. Thus, additional studies are needed to determine whether chlamydial veterinary pathogens and environmental CLOs can transfer antibiotic resistance genes to $C$. suis, C. trachomatis, or C. pneumoniae.

Recent studies suggest treatment failure during human genital infection results from incomplete eradication of simultaneous chronic GI infection, which re-establishes genital tract infection after therapy. Rank and Yeruva proposed a number of interesting mechanisms by which Chlamydiae in the GI tract might escape AZM therapy [59••]. However, it is also important to consider the role of (i) varied local GI $\mathrm{O}^{2}$ or nutrient concentrations, (ii) infection of GI cells in different developmental states, and/or (iii) induction of $\mathrm{AB}$ formation by stressors in the GI environment, the latter of which is consistent with the observation of $C$. suis $\mathrm{AB}$ within the GI epithelium of infected pigs [57]. It seems likely that Chlamydiae infect multiple host cell types/locations within the GI tract, which vary in physiological status and/or extracellular environment. In certain host cell types or nutrient-rich areas, chlamydial development would progress rapidly — releasing infectious EB. In other host cell types, or more stressful microenvironments, chlamydial development would be slowed or halted by the stress response-which could provide a treatment-resistant reservoir of Chlamydiae. Thus, further dissection of the mechanisms by which Chlamydiae establish chronic GI infection and evade antibiotic action is warranted. More importantly, though DOX appears more effective than AZM for eradicating GI/rectal chlamydial infection [63・•, $67 \bullet \cdot$, more extensive case-controlled studies in humans are a high priority. 
Though many advances in understanding chlamydial biology have been made over the last decade, the spectrum of effective anti-chlamydials has remained nearly unchanged (reviewed by $[15 \bullet \bullet]$ ). Sustained AZM therapy has also been associated with increased adverse cardiovascular events in patients [75], raising the possibility that higher or repeated AZM doses to eliminate GI carriage might be contraindicated. Finally, emergence of homotypic antibiotic resistance in human Chlamydiae remains a threat. Thus, development of novel anti-chlamydials is a high priority. The dozens of recently identified candidates are beyond the scope of this review but include type III secretion (T3S) inhibitors, chlamydial enzyme inhibitors, and compounds that block essential host cell functions. For example, modified forms of a salicylidene acylhydrazide T3S inhibitor inhibit $C$. muridarum, $C$. pneumoniae, and C. trachomatis serovar D inclusion development and EB production in culture [76]. The peptide deformylase inhibitor GM6001 inhibits C. trachomatis L2 inclusion development in culture and reduces vaginal shedding from C. muridarum-infected mice by $>100$-fold [77]. The antiviral compound ST-669 also reduces C. muridarum, C. trachomatis $\mathrm{L} 2$, and Chlamydia caviae growth in culture, possibly by a host lipid droplet-dependent mechanism [78]. Interestingly, exposure to JO146, an inhibitor of the chlamydial protease HtrA, significantly reduces $C$. trachomatis EB production when stressed chlamydiae re-enter developmental cycle [79]. JO146 also inhibits growth of $C$. trachomatis clinical strains in culture [80]. Thus, if chlamydial stress induction contributes to treatment failure in vivo, HtrA inhibitors might be used to increase AZM therapy success. Though recent studies indicate that peptidoglycan (PPG) synthesis inhibitors disrupt cell division in both Chlamydiae and CLO [81••, 82], caution in targeting PPG synthesis as a potential drug target is warranted due to the observation that $\beta$-lactams induce chlamydial stress $[4,83,84]$. Regardless, given the recent rectal/GI infection data, it is particularly important that potential anti-chlamydials be tested for efficacy in animal models of GI and genital infection before proceeding to clinical trials.

Acknowledgments This work was supported by NIH/NIAID R01AI095637, NIH/NCRR 1C06 RR030651, and Swiss National Fund grant 310030-147026.

Author Contributions All authors contributed to the literature review, writing, reading, and approving the manuscript.

\section{Compliance with Ethical Standards}

Conflict of Interest The authors declare that they have no competing interests.

Human and Animal Rights and Informed Consent This article does not contain any studies with human or animal subjects performed by any of the authors.
Open Access This article is distributed under the terms of the Creative Commons Attribution 4.0 International License (http:// creativecommons.org/licenses/by/4.0/), which permits unrestricted use, distribution, and reproduction in any medium, provided you give appropriate credit to the original author(s) and the source, provide a link to the Creative Commons license, and indicate if changes were made.

\section{References}

Papers of particular interest, publish recently, have been highlighted as:

- Of importance

.. Of major importance

1. Bavoil PM. What's in a word: the use, misuse, and abuse of the word "persistence" in Chlamydia biology. Front Cell Infect Microbiol. 2014;4:27.

2. Wyrick PB. Chlamydia trachomatis persistence in vitro: an overview. J Infect Dis. 2010;201:88-95.

3. Schoborg RV. Chlamydia persistence - a tool to dissect chlamydiahost interactions. Microbes Infect. 2011;13:649-62.

4. Kintner J, Lajoie D, Hall J, Whittimore J, Schoborg RV. Commonly prescribed $\beta$-lactam antibiotics induce $C$. trachomatis persistence/ stress in culture at physiologically relevant concentrations. Front Cell Infect Microbiol. 2014;4:44

5. Phillips Campbell R, Kintner J, Whittimore J, Schoborg RV. Chlamydia muridarum enters a viable but non-infectious state in amoxicillin-treated BALB/c mice. Microbes Infect. 2012;14: 1177-85.

6. Mariotti SP, Pascolini D, Rose-Nussbaumer J. Trachoma: global magnitude of a preventable cause of blindness. Br J Ophthalmol. 2009;93:563-8.

7. World Health Organization. Global incidence and prevalence of selected curable sexually transmitted infections-2008. 2012. doi: 10.1016/S0968-8080(12)40660-7.

8. Marrazzo J, Suchland R. Recent advances in understanding and managing Chlamydia trachomatis infections. F1000Prime Rep. 2014;6:120

9. Owusu-Edusei K, Chesson HW, Gift TL, Tao G, Mahajan R, Ocfemia MCB, et al. The estimated direct medical cost of selected sexually transmitted infections in the United States, 2008. Sex Transm Dis. 2013;40:197-201.

10. Al-Younes HM. High prevalence of Chlamydia pneumoniae infection in an asymptomatic Jordanian population. J Microbiol Immunol Infect. 2014;47:412-7.

11. Tewari R, Nijhawan V, Mishra M, Dudeja P, Salopal T. Prevalence of Helicobacter pylori, cytomegalovirus, and Chlamydia pneumoniae immunoglobulin seropositivity in coronary artery disease patients and normal individuals in North Indian population. Med Journal, Armed Forces India. 2012;68:53-7.

12. Eick AA, Faix DJ, Tobler SK, Nevin RL, Lindler LE, Hu Z, et al. Serosurvey of bacterial and viral respiratory pathogens among deployed U.S. service members. Am J Prev Med. 2011;41:573-80.

13. Kuo CC, Jackson LA, Campbell LA, Grayston JT. Chlamydia pneumoniae (TWAR). Clin Microbiol Rev. 1995;8:451-61.

14. Centers for Disease Control and Prevention. Sexually Transmitted Diseases Treatment Guidelines, 2015. 2015;64:1-137.

15.• Kohlhoff SA, Hammerschlag MR. Treatment of Chlamydial infections: 2014 update. Expert Opin Pharmacother. 2015;16:205-12. A recent review covering current treatment guidelines for human chlamydial infections, as well as spectrum of in vitro antimicrobial susceptability. 
16. Schautteet K, Vanrompay D. Chlamydiaceae infections in pig. Vet Res. 2011;42:29.

17. Dean D, Rothschild J, Ruettger A, Kandel RP, Sachse K. Zoonotic Chlamydiaceae species associated with trachoma, Nepal. Emerg Infect Dis. 2013;19:1948-55.

18. De Puysseleyr K, De Puysseleyr L, Dhondt H, Geens T, Braeckman L, Morré SA, et al. Evaluation of the presence and zoonotic transmission of Chlamydia suis in a pig slaughterhouse. BMC Infect Dis. 2014;14:560.

19. De Puysseleyr K, De Puysseleyr L, Geldhof J, Cox E, Vanrompay D. Development and validation of a real-time PCR for Chlamydia suis diagnosis in swine and humans. PLoS One. 2014;9:e96704.

20. Binet R, Maurelli AT. Frequency of development and associated physiological cost of azithromycin resistance in Chlamydia psittaci 6BC and C. trachomatis L2. Antimicrob Agents Chemother. 2007;51:4267-75.

21. Binet R, Bowlin AK, Maurelli AT, Rank RG. Impact of azithromycin resistance mutations on the virulence and fitness of Chlamydia caviae in guinea pigs. Antimicrob Agents Chemother. 2010;54:1094-101.

22. Black LA, Higgins DP, Govendir M. In vitro activity of chloramphenicol, florfenicol and enrofloxacin against Chlamydia pecorum isolated from koalas (Phascolarctos cinereus). Aust Vet J. 2015;93: 420-3.

23. Donati M, Huot-Creasy H, Humphrys M, Di Paolo M, Di Francesco A, Myers GSA. Genome Sequence of Chlamydia suis MD56, Isolated from the Conjunctiva of a Weaned Piglet. Genome Announc 2014;2.

24. Chopra I, Roberts M. Tetracycline antibiotics: mode of action, applications, molecular biology, and epidemiology of bacterial resistance. Microbiol Mol Biol Rev. 2001;65:232-60.

25. Nguyen F, Starosta AL, Arenz S, Sohmen D, Dönhöfer A, Wilson DN. Tetracycline antibiotics and resistance mechanisms. Biol Chem. 2014;395:559-75.

26. Andersen A, Rogers D. Resistance to tetracycline and sulphadiazine in swine C. trachomatis isolates. In: Stephens R, editor. Proc. 9th Int. syposium Hum. chlamydial Infect., San Francisco, CA. USA.: 1998, p. 313-6.

27. Lenart J, Andersen AA, Rockey DD. Growth and development of tetracycline-resistant Chlamydia suis. Antimicrob Agents Chemother. 2001;45:2198-203. doi:10.1128/AAC.45.8.21982203.2001.

28. Dugan J, Rockey DD, Jones L, Andersen AA. Tetracycline resistance in Chlamydia suis mediated by genomic islands inserted into the chlamydial inv-like gene. Antimicrob Agents Chemother. 2004;48:3989-95. doi:10.1128/AAC.48.10.3989-3995.2004.

29. Dugan J, Andersen AA, Rockey DD. Functional characterization of IScs605, an insertion element carried by tetracycline-resistant Chlamydia suis. Microbiology. 2007;153:71-9.

30. Sandoz KM, Rockey DD. Antibiotic resistance in Chlamydiae. Future Microbiol. 2010;5:1427-42.

31. Suchland RJ, Sandoz KM, Jeffrey BM, Stamm WE, Rockey DD. Horizontal transfer of tetracycline resistance among Chlamydia spp. in vitro. Antimicrob Agents Chemother. 2009;53:4604-11.

32. Tian R-M, Cai L, Zhang W-P, Cao H-L, Qian P-Y. Rare events of intragenus and intraspecies horizontal transfer of the 16S rRNA gene. Genome Biol Evol. 2015;7:2310-20.

33. Di Francesco A, Donati M, Rossi M, Pignanelli S, Shurdhi A, Baldelli R, et al. Tetracycline-resistant Chlamydia suis isolates in Italy. Vet Rec. 2008;163:251-2.

34. Borel N, Regenscheit N, Di Francesco A, Donati M, Markov J, Masserey Y, et al. Selection for tetracycline-resistant Chlamydia suis in treated pigs. Vet Microbiol. 2012;156:143-6.

35. Pignanelli S, Shurdhi A. In vitro activity of rifaximin against Chlamydia suis. Vet Rec. 2011;169:584.
36. Schautteet K, De Clercq E, Miry C, Van Groenweghe F, Delava P, Kalmar I, et al. Tetracycline-resistant Chlamydia suis in cases of reproductive failure on Belgian, Cypriote and Israeli pig production farms. J Med Microbiol. 2013;62:331-4.

37. Hong KC, Schachter J, Moncada J, Zhou Z, House J, Lietman TM. Lack of macrolide resistance in Chlamydia trachomatis after mass azithromycin distributions for trachoma. Emerg Infect Dis. 2009;15:1088-90.

38. West SK, Moncada J, Munoz B, Mkocha H, Storey P, Hardick J, et al. Is there evidence for resistance of ocular Chlamydia trachomatis to azithromycin after mass treatment for trachoma control? J Infect Dis. 2014;210:65-71. An elegant recent study demonstrating no evidence for chlamydial homotypic resistance after a mass treatment program.

39. Ljubin-Sternak S, Mestrovic T, Vilibic-Cavlek T, MlinaricGalinovic G, Sviben M, Markotic A, et al. In vitro susceptibility of urogenital Chlamydia trachomatis strains in a country with high azithromycin consumption rate. Folia Microbiol (Praha). 2013;58: 361-5.

40. Golden MR, Whittington WLH, Handsfield HH, Hughes JP, Stamm WE, Hogben M, et al. Effect of expedited treatment of sex partners on recurrent or persistent gonorrhea or chlamydial infection. N Engl J Med. 2005;352:676-85.

41. Batteiger BE, Tu W, Ofner S, Van Der Pol B, Stothard DR, Orr DP, et al. Repeated Chlamydia trachomatis genital infections in adolescent women. J Infect Dis. 2010;201:42-51.

42. Horner PJ. Azithromycin antimicrobial resistance and genital Chlamydia trachomatis infection: duration of therapy may be the key to improving efficacy. Sex Transm Infect. 2012;88:154-6.

43. Pitt RA, Alexander S, Horner PJ, Ison CA. Presentation of clinically suspected persistent chlamydial infection: a case series. Int J STD AIDS. 2013;24:469-75.

44. Hocking JS, Kong FYS, Timms P, Huston WM, Tabrizi SN. Treatment of rectal chlamydia infection may be more complicated than we originally thought. J Antimicrob Chemother. 2015;70:961-4.

45. Bhengraj AR, Vardhan H, Srivastava P, Salhan S, Mittal A. Decreased susceptibility to azithromycin and doxycycline in clinical isolates of Chlamydia trachomatis obtained from recurrently infected female patients in India. Chemotherapy. 2010;56:371-7.

46. O'Neill CE, Seth-Smith HMB, Van Der Pol B, Harris SR, Thomson NR, Cutcliffe LT, et al. Chlamydia trachomatis clinical isolates identified as tetracycline resistant do not exhibit resistance in vitro: whole-genome sequencing reveals a mutation in porB but no evidence for tetracycline resistance genes. Microbiology. 2013;159:748-56.

47. Törmäkangas L, Markkula E, Lounatmaa K, Puolakkainen M. Chlamydia pneumoniae infection in polarized epithelial cell lines. Infect Immun. 2010;78:2714-22.

48. Shima K, Szaszák M, Solbach W, Gieffers J, Rupp J. Impact of a low-oxygen environment on the efficacy of antimicrobials against intracellular Chlamydia trachomatis. Antimicrob Agents Chemother. 2011;55:2319-24.

49. Shima K, Klinger M, Solbach W, Rupp J. Activities of first-choice antimicrobials against gamma interferon-treated Chlamydia trachomatis differ in hypoxia. Antimicrob Agents Chemother. 2013;57:2828-30.

50. Kutlin A, Roblin PM, Hammerschlag MR. In vitro activities of azithromycin and ofloxacin against Chlamydia pneumoniae in a continuous-infection model. Antimicrob Agents Chemother. 1999;43:2268-72.

51. Wyrick PB, Knight ST. Pre-exposure of infected human endometrial epithelial cells to penicillin in vitro renders Chlamydia trachomatis refractory to azithromycin. J Antimicrob Chemother. 2004;54:79-85. 
52. Reveneau N, Crane DD, Fischer E, Caldwell HD. Bactericidal activity of first-choice antibiotics against gamma interferon-induced persistent infection of human epithelial cells by Chlamydia trachomatis. Antimicrob Agents Chemother. 2005;49:1787-93.

53. Phillips-Campbell R, Kintner J, Schoborg RV. Induction of the Chlamydia muridarum stress/persistence response increases azithromycin treatment failure in a murine model of infection. Antimicrob Agents Chemother. 2014;58:1782-4. The first demonstration that entry into the chlamydial stress response may contribute to azithromycin treatment failure in vivo.

54. Nanagara R, Li F, Beutler A, Hudson A, Schumacher HR. Alteration of Chlamydia trachomatis biologic behavior in synovial membranes. Suppression of surface antigen production in reactive arthritis and Reiter's syndrome. Arthritis Rheum. 1995;38:1410-7.

55. Skowasch D, Yeghiazaryan K, Schrempf S, Golubnitschaja O, Welsch U, Preusse CJ, et al. Persistence of Chlamydia pneumoniae in degenerative aortic valve stenosis indicated by heat shock protein 60 homologues. J Heart Valve Dis. 2003;12:68-75.

56. Lewis ME, Belland RJ, AbdelRahman YM, Beatty WL, Aiyar AA, Zea AH, et al. Morphologic and molecular evaluation of Chlamydia trachomatis growth in human endocervix reveals distinct growth patterns. Front Cell Infect Microbiol. 2014;4:71. This manuscript definitively demonstates that chlamydiae enter the stress response/aberrent RB phenotype within human genital tract tissues.

57. Pospischil A, Borel N, Chowdhury EH, Guscetti F. Aberrant chlamydial developmental forms in the gastrointestinal tract of pigs spontaneously and experimentally infected with Chlamydia suis. Vet Microbiol. 2009;135:147-56.

58. Rank RG, Whittimore J, Bowlin AK, Wyrick PB. In vivo ultrastructural analysis of the intimate relationship between polymorphonuclear leukocytes and the chlamydial developmental cycle. Infect Immun. 2011;79:3291-301.

59.• Rank RG, Yeruva L. Hidden in plain sight: chlamydial gastrointestinal infection and its relevance to persistence in human genital infection. Infect Immun. 2014;82:1362-71. A review of veterinary and chlamydial GI infections. The authors also extensively discuss mechanisms by which chlamydiae might establish chronic GI infections and contribute to treatment failure in humans.

60. Perry LL, Hughes S. Chlamydial colonization of multiple mucosae following infection by any mucosal route. Infect Immun. 1999;67: 3686-9.

61. Igietseme JU, Portis JL, Perry LL. Inflammation and clearance of Chlamydia trachomatis in enteric and nonenteric mucosae. Infect Immun. 2001;69:1832-40.

62. Yeruva L, Spencer N, Bowlin AK, Wang Y, Rank RG. Chlamydial infection of the gastrointestinal tract: a reservoir for persistent infection. Pathog Dis. 2013;68:88-95.

63.• Yeruva L, Melnyk S, Spencer N, Bowlin A, Rank RG. Differential susceptibilities to azithromycin treatment of chlamydial infection in the gastrointestinal tract and cervix. Antimicrob Agents Chemother. 2013;57:6290-4. The first report in an animal model system demonstrating that GI and genital chlamydial infections have differential sensitivities to azithromycin and doxycycline.

64. Ding A, Challenor R. Rectal Chlamydia in heterosexual women: more questions than answers. Int J STD AIDS. 2013;25:587-92.

65. Van Liere GAFS, Hoebe CJPA, Wolffs PFG, Dukers-Muijrers NHTM. High co-occurrence of anorectal chlamydia with urogenital chlamydia in women visiting an STI clinic revealed by routine universal testing in an observational study; a recommendation towards a better anorectal chlamydia control in women. BMC Infect Dis. 2014;14:274.

66. Khosropour CM, Dombrowski JC, Barbee LA, Manhart LE, Golden MR. Comparing azithromycin and doxycycline for the treatment of rectal chlamydial infection: a retrospective cohort study. Sex Transm Dis. 2014;41:79-85.
67.• Kong FYS, Tabrizi SN, Fairley CK, Vodstrcil LA, Huston WM, Chen M, et al. The efficacy of azithromycin and doxycycline for the treatment of rectal chlamydia infection: a systematic review and meta-analysis. J Antimicrob Chemother. 2015;70:1290-7. An extensive review of azithromycin and doxycycline efficacy in human rectal chlamydial infections.

68. Craig AP, Kong FY, Yeruva L, Hocking JS, Rank RG, Wilson DP, et al. Is it time to switch to doxycycline from azithromycin for treating genital chlamydial infections in women? Modelling the impact of autoinoculation from the gastrointestinal tract to the genital tract. BMC Infect Dis. 2015;15:200.

69. Jones RB, Rabinovitch RA, Katz BP, Batteiger BE, Quinn TS, Terho $\mathrm{P}$, et al. Chlamydia trachomatis in the pharynx and rectum of heterosexual patients at risk for genital infection. Ann Intern Med. 1985;102:757-62.

70. Zhang Q, Huang Y, Gong S, Yang Z, Sun X, Schenken R, et al. In vivo and ex vivo imaging reveals a long-lasting chlamydial infection in the mouse gastrointestinal tract following genital tract inoculation. Infect Immun. 2015;83:3568-77. This paper describes an in vivo imaging technique that could be used to monitor chronic vaginal and GI infection in real time during treatment with investigational anti-chlamydial drugs.

71. Taylor-Brown A, Vaughan L, Greub G, Timms P, Polkinghorne A. Twenty years of research into Chlamydia-like organisms: a revolution in our understanding of the biology and pathogenicity of members of the phylum Chlamydiae. Pathog Dis. 2015;73:1-15. This review provides an extensive overview of Chlamydia-like organism research, emphasizing the biological and genomic diversity of these emerging pathogens.

72. De Barsy M, Bottinelli L, Greub G. Antibiotic susceptibility of Estrella lausannensis, a potential emerging pathogen. Microbes Infect. 2014;16:746-54.

73. Casson N, Greub G. Resistance of different Chlamydia-like organisms to quinolones and mutations in the quinoline resistancedetermining region of the DNA gyrase A- and topoisomeraseencoding genes. Int J Antimicrob Agents. 2006;27:541-4.

74. Vouga M, Diabi H, Boulos A, Baud D, Raoult D, Greub G. Antibiotic susceptibility of Neochlamydia hartmanellae and Parachlamydia acanthamoebae in amoebae. Microbes Infect 2015

75. Ray WA, Murray KT, Hall K, Arbogast PG, Stein CM. Azithromycin and the risk of cardiovascular death. N Engl J Med. 2012;366:1881-90.

76. Bao X, Gylfe A, Sturdevant GL, Gong Z, Xu S, Caldwell HD, et al. Benzylidene acylhydrazides inhibit chlamydial growth in a type III secretion- and iron chelation-independent manner. J Bacteriol. 2014;196:2989-3001.

77. Balakrishnan A, Wang L, Li X, Ohman-Strickland P, Malatesta P, Fan H. Inhibition of chlamydial infection in the genital tract of female mice by topical application of a peptide deformylase inhibitor. Microbiol Res. 2009;164:338-46.

78. Sandoz KM, Valiant WG, Eriksen SG, Hruby DE, Allen RD, Rockey DD. The broad-spectrum antiviral compound ST-669 restricts chlamydial inclusion development and bacterial growth and localizes to host cell lipid droplets within treated cells. Antimicrob Agents Chemother. 2014;58:3860-6.

79. Ong VA, Marsh JW, Lawrence A, Allan JA, Timms P, Huston WM. The protease inhibitor JO146 demonstrates a critical role for CtHtrA for Chlamydia trachomatis reversion from penicillin persistence. Front Cell Infect Microbiol. 2013;3:100.

80. 80. Ong VA, Lawrence A, Timms P, Vodstrcil LA, Tabrizi SN, Beagley KW, et al. In vitro susceptibility of recent Chlamydia trachomatis clinical isolates to the CtHtrA inhibitor JO146. Microbes Infect 2015.

81.• Packiam M, Weinrick B, Jacobs WR, Maurelli AT. Structural characterization of muropeptides from Chlamydia trachomatis peptidoglycan by mass spectrometry resolves "chlamydial anomaly". Proc 
Natl Acad Sci U S A. 2015;112:11660-5. An elegant dissection of peptidoglycan structural elements in the chlamydiae and resolution of the "chlamydial anomaly".

82. Jacquier N, Frandi A, Viollier PH, Greub G. Disassembly of a medial transenvelope structure by antibiotics during intracellular division. Chem Biol. 2015;22:1217-27.
83. Storey C, Chopra I. Affinities of beta-lactams for penicillin binding proteins of Chlamydia trachomatis and their antichlamydial activities. Antimicrob Agents Chemother. 2001;45:303-5.

84. Ouellette SP, Karimova G, Subtil A, Ladant D. Chlamydia co-opts the rod shape-determining proteins MreB and $\mathrm{Pbp} 2$ for cell division. Mol Microbiol. 2012;85:164-78. 